\title{
Net-zero Energy Building Clusters Emulator for Energy Planning and Operation Evaluation
}

\begin{abstract}
The emergence of smart grids, Net-zero energy buildings, and advanced building energy demand response technologies continuously drives the needs for better design and operation strategies for buildings and distributed energy systems. It is envisioned that similar to micro-communities in a human society, neighboring buildings will have the tendency to form a building cluster, an open cyber-physical system to exploit the economic opportunities provided by smart grids and distributed energy systems. To realize this building cluster envision, it requires better urban energy planning and operation control strategies to determine which type of buildings should be clustered and what operation strategies should be implemented to fully utilize the potential in load aggregation, load shifting, and resource allocation. However, most of the current tools are focusing on single buildings or devices, which are not suitable for building cluster studies. To this end, this study proposes to develop a Net-zero building cluster emulator that can simulate realistic energy behaviors of a cluster of buildings and their distributed energy devices as well as exchange operation data and control schemes with real-world building control systems. The developed emulator has the flexibility to integrate with different buildings and distributed energy systems to study the performance of this building cluster to propose suggestions in urban energy planning and operation. To show the application of this emulator, a proof-of-concept demonstration is also presented in this paper.
\end{abstract}

Keywords: Net-zero building cluster; Net-zero buildings; smart grids; distributed energy systems; cosimulation

\section{Introduction}

Buildings are responsible for more than $40 \%$ of primary energy and $70 \%$ of the electricity consumption in the United States [1], of which approximately $15-20 \%$ is wasted by nonoptimal control schemes and malfunction of equipment or performance degradation [2]. Moreover, the National Energy 
Technology Laboratory estimated that more than one-fourth of the 713 GW of US electricity demand in 2010 could be dispatchable if only buildings could respond to that dispatch through advanced building energy control and operation strategies and smart grid infrastructure [3]. Load dispatching is to determine the operation of generation facilities to produce energy at minimum cost to serve consumers reliably, which can assist the balance between power supply and demand in the power grids. Several distributed energy systems are developed and connected to the power grids, which brings in challenges to fully utilize the energy saving and reliability maintaining potentials. To this end, there is an urgent requirement to develop better control and operation strategies for buildings and distributed energy systems. Currently, with the spreading of smart grids, the power infrastructure in the United States is experiencing a revolutionary transformation, from a centralized one-way communication of power information to a decentralized network with two-way communication [4]. With the trend of moving from centralized building operation decision to decentralized operation control, it is envisioned that neighboring buildings will have the tendency to form a building cluster, within which smart grids, distributed power generation, and storage devices can freely share energy resource locally and globally and the entire cluster will achieve maximum energy efficiency [5].

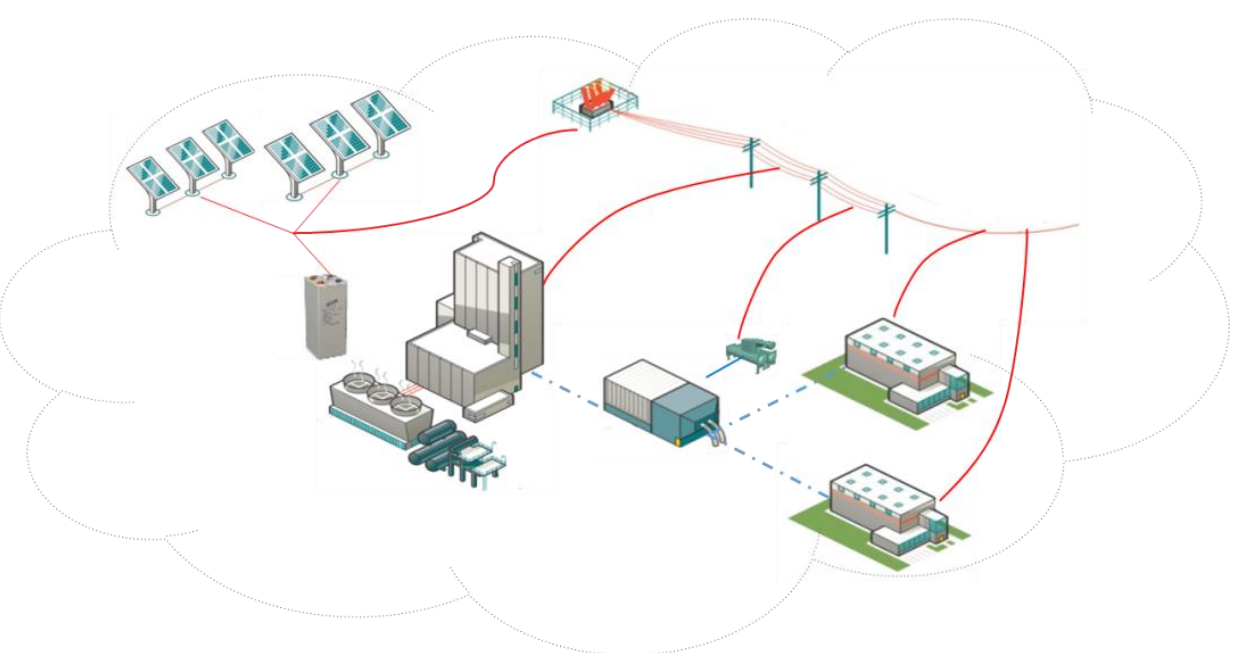

Figure 1. Building cluster connection and operation

In this direction, this study proposes a Net-zero building cluster concept (Figure 1). Different from the existing load aggregation concept, this building cluster concept may transform the energy industry by 
shifting expensive on-site energy generation aimed at creating single Net-zero building one-at-a-time to an autonomous and adaptive system of buildings aimed at Net-zero clusters. Through optimized demand management, these building clusters will likely reduce overall primary energy consumption and peak time electricity demand to be more resilient to power disruptions. Before this Net-zero building cluster concept, extensive studies have focused on Net-zero building development from the perspective of early design [6, 7], renewable energy system integration [8], and performance evaluation [9]. Together with the Net-zero building studies, research has also focused on developing operation strategies to improve energy efficiency, such as building energy forecasting [10,11], building temperature control $[12,13]$, distributed energy system integration $[14,15]$, and operation optimization and fault detection [16]. Even though these studies have made significant achievements, they focused on only single building and its interactions with distributed systems. Moreover, the benefits from Net-zero building cluster concept have not been fully investigated. A comprehensive review paper introduced and summarized the state of art of building and distributed energy systems studies [17], which also probed the necessities in studying interactions between different buildings, energy systems, and smart grids. The effectiveness of building cluster concept in improving energy efficiency and resilience has been proved in limited number of studies [1820]. All these studies, however, use simplified physics based models or data-driven models for operation simulation and control strategy determination. The results from those highly simplified models are difficult to verify against the reality of complex building clusters. Therefore, this study proposes to develop a building cluster emulator that can simulate the operation of multiple buildings and distributed energy systems, and especially device sharing and resources allocation, by using more sophisticated simulation tools to verify and assess the proposed building cluster formation and operation schemes.

Most building energy simulation tools, unfortunately, focus only on single building or single energy system. For example, EnergyPlus [21] is a detailed physics-based whole building simulation program that can simulate the targeted building energy consumption from HVAC, lighting, and other equipment. TRNSYS is another flexible graphics-based software environment used to simulate the behavior of transient systems. There are also several studies focusing on developing distributed energy system models 
in TRNSYS, such as PV panels models [22] and battery models [23]. To the best of the authors' knowledge, no simulation tool exists that can simulate the Net-zero building cluster cases proposed in this study. The proposed Net-zero building cluster emulator selects detailed physics-based simulation models for buildings and distributed energy systems in EnergyPlus and TRNSYS. These models are detailed enough to be used to assess the effectiveness of various control strategies, and have been experimentally validated in previous studies. To link all these models together and to enable simultaneous simulation, this emulator uses a Building Controls Virtual Test Bed (BCVTB) developed by LBNL [24]. After various models are assembled to form a building cluster emulator, a proof-of-concept operation demonstration is then presented. In this demonstration, only two buildings, one ice tank, one PV panel, and one battery are included in this building cluster, but the emulator has the flexibility to integrate more buildings and devices. Section 1 describes the overall structure of this emulator, followed by the detailed information about the module development and connection in Sections 2 and 3. Finally, Section 4 presents testing criteria of the proof-of-concept demonstration and the simulated results.

\section{Emulator Overall Design and Operation}

\subsection{Emulator Design}

The overall emulator design and connection are illustrated in Figure 2. In this emulator, there are four simulation modules: building module, ice tank module, PV-battery module, and operation module. Besides these simulation modules, there is a simulation operation module, which contains a database for simulation conditions and operation strategies, and a simulation result analysis model. The PV-battery module and the ice tank module are shared within this building cluster. EnergyPlus is chosen to simulate the buildings and ice tank thermal storage devices, because it is widely used and validated to provide detailed simulation results at a minimum 1-min time step. TRNSYS is selected to simulate the PV panel power generation and battery system. Operation module, which can provide the control and operation strategies, is present in MATLAB. BCVTB serves as a middleware to connect all the simulation models. 

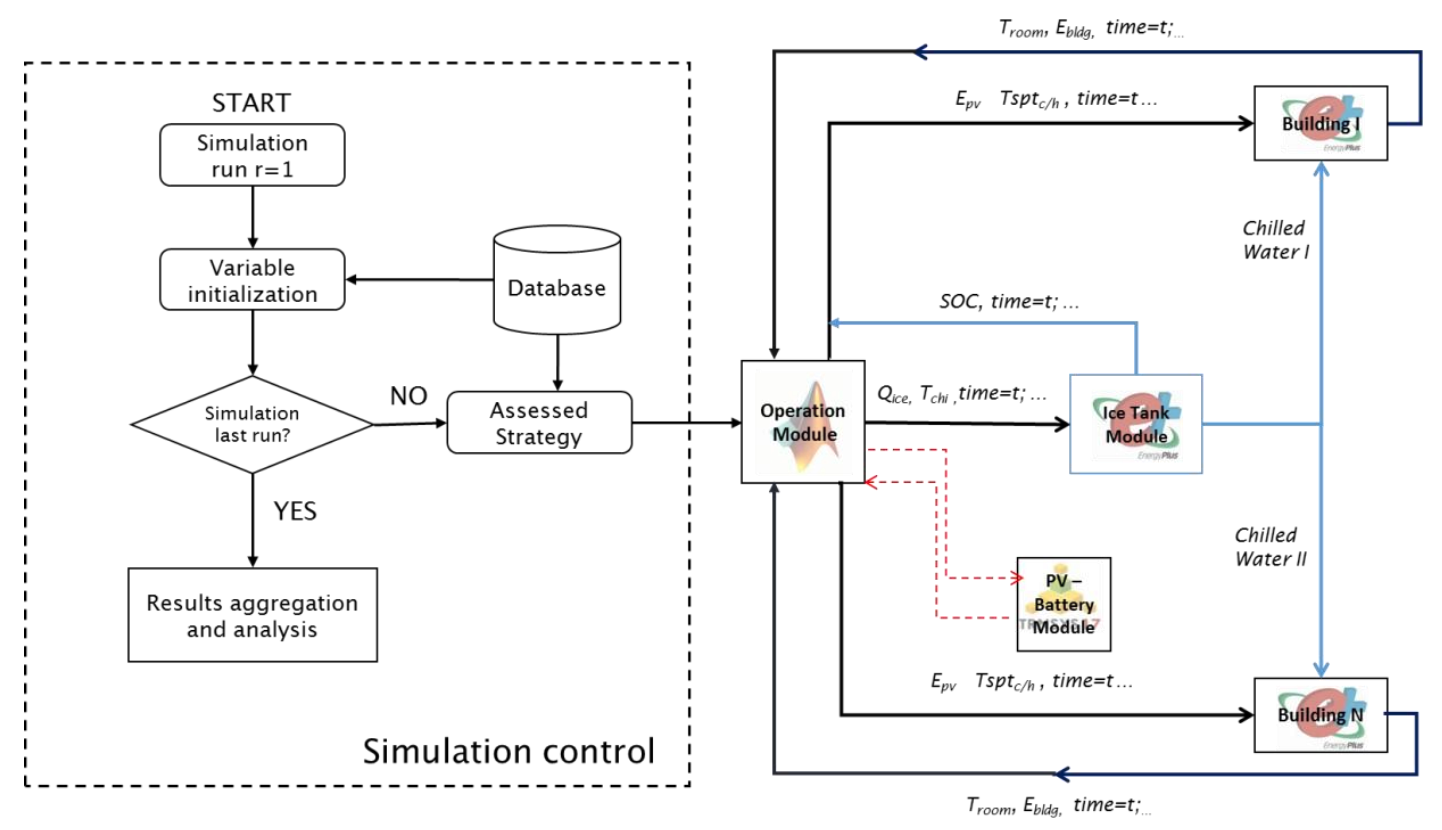

Figure 2. Emulator operation control diagram

\subsection{Emulator Operation}

The emulator will store control and operation schemes in the database and apply them in each module within this cluster through MATLAB and BCVTB. Table 1 summarizes the major inputs and outputs of each module.

Table 1. Building Cluster Input-Output Summary

\begin{tabular}{|c|c|c|}
\hline Simulation Module & Input & Major Output \\
\hline Building model & $\begin{array}{l}\mathrm{T}_{\text {seph }} \text { (heating setpoint) } \\
\mathrm{T}_{\text {sepc }}(\text { cooling setpoint) }\end{array}$ & $\begin{array}{c}\mathrm{E}_{\mathrm{b}} \text { (building energy consumption), } \mathrm{E}_{\mathrm{dc}} \text { (dedicated chiller energy } \\
\text { consumption), } \mathrm{E}_{\mathrm{bc}} \text { (base chiller energy consumption), } \mathrm{T}_{\text {zone }} \text { (building } \\
\text { zone temperature), } \mathrm{H}_{\text {zone }} \text { (Building zone humidity) }\end{array}$ \\
\hline Ice tank & $\mathrm{S}_{\mathrm{i}}$ (operation state of ice tank) & $\begin{array}{l}\mathrm{SOC}_{\text {ice }} \text { (ice tank state of charge), } \mathrm{E}_{\text {ice }} \text { (charging and discharging } \\
\text { rate), } \mathrm{T}_{\text {chlw }} \text { (chilled water in/out temperature), } \mathrm{M}_{\text {chlw }} \text { (chilled water } \\
\text { in/out temperature flow rate) }\end{array}$ \\
\hline Battery model & $\mathrm{S}_{\mathrm{b}}$ (operation state of battery) & $\begin{array}{c}\mathrm{SOC}_{\text {bat }} \text { (battery state of battery), } \mathrm{E}_{\text {bat }} \text { (charging and discharging rate), } \\
\mathrm{I}_{\text {bat }} \text { (charging and discharging current) }\end{array}$ \\
\hline PV model & $\mathrm{S}_{\mathrm{pv}}$ (operation state of PV panel) & $\mathrm{E}_{\mathrm{pv}}($ Power generation $)$ \\
\hline Power grid model & $\begin{array}{l}\mathrm{E}_{\mathrm{p}} \text { (Power buying from power grid) } \\
\mathrm{E}_{\mathrm{s}} \text { (Power selling to power grid) }\end{array}$ & $\begin{array}{c}\left.\mathrm{R}_{\text {tou }}(\text { Time-of-use price }), \mathrm{P}_{\mathrm{c}} \text { (electricity costs }\right) \\
\mathrm{P}_{\mathrm{e}}(\text { electricity earnings })\end{array}$ \\
\hline
\end{tabular}

At each simulation time step, the emulator provides real-world-like noisy and noise-free "measurements" according to the simulation results, such as energy generation and performance data of energy storage devices. The control signals sent from the operation module are building heating and cooling setpoints $\left(\mathrm{T}_{\mathrm{seph}}, \mathrm{T}_{\mathrm{sepc}}\right)$, operation energy generation and storage $\left(\mathrm{S}_{i}, \mathrm{~S}_{\mathrm{b}}, \mathrm{S}_{\mathrm{pv}}\right)$, and electricity 
purchasing and selling $\left(\mathrm{E}_{\mathrm{p}}, \mathrm{E}_{\mathrm{s}}\right)$; of these signals, the first two are sent to the building module, $\mathrm{S}_{\mathrm{i}}$ is sent to the ice tank module, $S_{b}$ and $S_{p v}$ are sent to PV-battery module, and $E_{p}$ and $E_{s}$ are sent to the simulation operation module. Meanwhile, building measurements $\left(\mathrm{E}_{\mathrm{b}}, \mathrm{T}_{\mathrm{zone}}\right.$, etc.) are outputs from the building module, ice tank measurements $\left(\mathrm{SOC}_{\text {ice }}, \mathrm{T}_{\text {chlw }}, \mathrm{M}_{\text {chlw }}\right.$, and $\left.\mathrm{E}_{\mathrm{ice}}\right)$ are output from the ice tank module, $\mathrm{PV}$ battery measurements $\left(\mathrm{E}_{\mathrm{pv}}, \mathrm{E}_{\mathrm{bat}}\right.$, and $\left.\mathrm{SOC}_{\mathrm{bat}}\right)$ are output from the PV-battery module, and $\mathrm{P}_{\text {tou }}, \mathrm{P}_{\mathrm{c}}$, and $\mathrm{P}_{\mathrm{e}}$ are output from the power grid module. All these outputs will be transferred to the simulation operation module to assess the control strategies at each time step and a set of new control signals will then be sent to the cluster.

\section{Emulator Module Development}

\subsection{Building Module}

Although the test bed can include any number and type of EnergyPlus building models, only two different buildings are included in this demonstration. Building simulation models for two typical medium-size office buildings in Philadelphia developed in a previous study are selected for this cluster emulator [25]. This first building is a one-story, $464.5-\mathrm{m}^{2}$ commercial building and the other one is a three-story, $1393.55-\mathrm{m}^{2}$ commercial building. The window-to-wall ratio for both buildings is approximately 0.29 . The windows are of various single- and double-pane construction with 3- and 6-mm glass and either 6- or 13-mm argon or air gap. The U-factors of the single- and double-pane windows are 0.173 and $0.086 \mathrm{~W} / \mathrm{m}^{2} \mathrm{~K}$, respectively. Both buildings have deck roofs with $\mathrm{R}-15$ insulation and solar absorptivity of 0.9. A summary of the heat gains is presented in Table 2. The first building system is a single-duct constant air volume (CAV) rooftop unit (RTU) system, and the other one is a single-duct CAV air-handling unit (AHU) system.

Table 2. Building Internal and External Heat Gains

\begin{tabular}{ccc}
\hline Heat Source & Value & Unit \\
\hline Occupant & 0.1 & Person/square meter \\
Ventilation & 0.0125 & Cubic meter/second person \\
Lighting power & 15 & Watts/square meter \\
Interior Plug Loads & 10 & Watts/square meter \\
Envelope Infiltration & $9.4 \mathrm{E}-4$ & Cubic meter/second square meter \\
\hline
\end{tabular}


A summary of the mechanical systems is presented in Table 3. The first building system is a singleduct CAV RTU system and the other one is a single-duct CAV AHU system.

\section{Table 3.Building Mechanical Systems}

\begin{tabular}{ccc}
\hline & Building I & Building II \\
\hline System & 3 CAV, RTUs & 3 CAV, AHUs \\
Main Cooling Coil & DX, COP 3 & Chilled water \\
Main Heating Coil & Hot water & Hot water \\
Zone Reheat & Hot water & Eclectic \\
Heat Plant & Central Boiler & Central Boiler \\
\hline
\end{tabular}

\subsection{PV-battery Module}

PV panel power generation and battery electricity storage are modeled together as a PV-battery module in this emulator. As shown in Figure 3, the PV-battery system module contains a PV panel model, a battery model, a power grid model, a local operation controller model, and two inverter models.

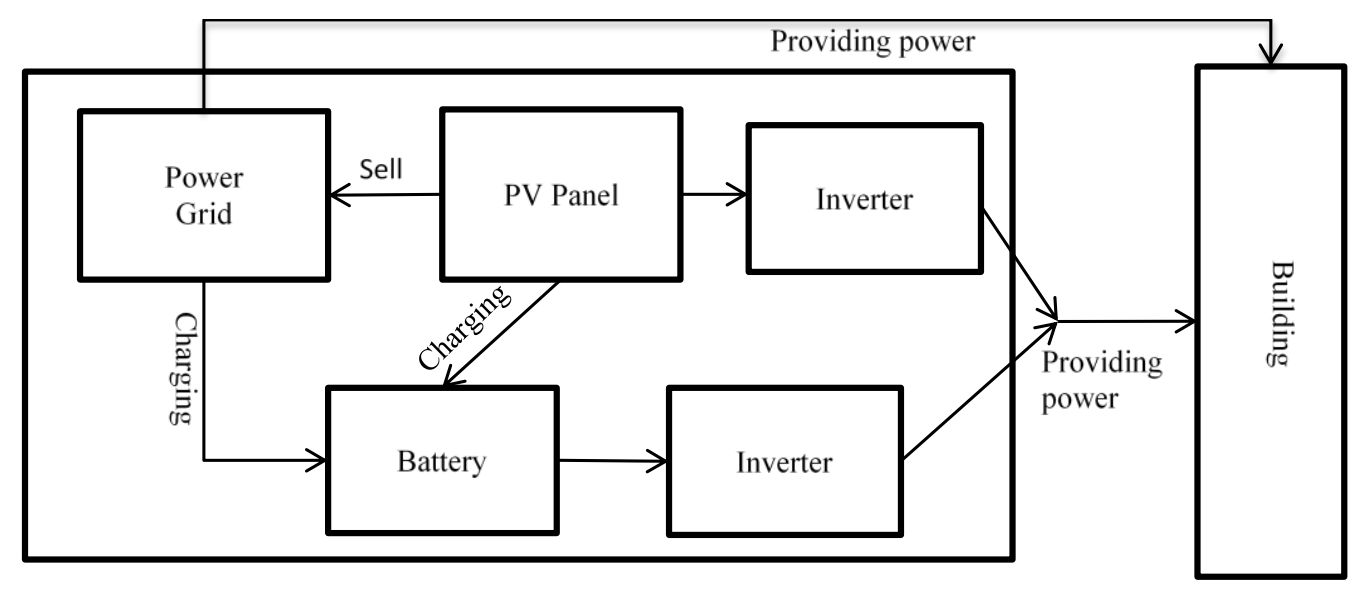

Figure 3. PV panel-battery system configuration

All these components are modeled individually and interconnected in TRNSYS. The PV panel is modeled using Type 194 in TRNSYS, which is based on the diode equivalent circuit model to calculate the power generation rate, outlet current, and voltage [26]:

$$
I=I_{L}-I_{0}\left[\exp \left(\frac{q}{\gamma k T_{c}}\left(V+I R_{S}\right)\right)-1\right],
$$


where $I$ is the PV module output current, $I_{L}$ is the module photocurrent, $I_{0}$ is the saturation current, $q$ is the electron charge constant, $\gamma$ is PV curve fitting parameter, $k$ is the Boltzmann constant, $T_{c}$ is the module temperature, $V$ is the $\mathrm{PV}$ module voltage, and $R_{S}$ is the module resistance. The major parameters used in PV panel TRNSYS model are summarized in Table 4.

Table 4. PV panel model parameter

\begin{tabular}{ccc}
\hline Parameter & Value & Unit \\
\hline Open circuit voltage & 21.6 & $\mathrm{~V}$ \\
Short circuit current & 6.5 & $\mathrm{~A}$ \\
Maximum power voltage & 17 & $\mathrm{~V}$ \\
Maximum power current & 5.9 & $\mathrm{~A}$ \\
Temperature coefficients at open circuit voltage & -0.079 & -- \\
Temperature coefficients at short circuit current & 0.02 & -- \\
Nominal operating cell temperature (NOCT) & 298 & $\mathrm{~K}$ \\
Insolation at NOCT & 800 & $\mathrm{~W} / \mathrm{m}^{2}$ \\
Number of modules in series & 51 & -- \\
Number of modules in parallel & 6 & -- \\
Module area & 0.89 & $\mathrm{~m}^{2}$ \\
\hline
\end{tabular}

The battery system is developed using Type $47 \mathrm{~b}$ in TRNSYS, which simulates a lead-acid storage battery in conjunction with PV panel. It specifies how the battery state of charge (SOC) varies over time, given the rate of charge and discharge. The parameters used in this project are illustrated in Table 5. The output of this module is the power provided to the buildings in this cluster.

Table 5. Battery model parameter

\begin{tabular}{ccc}
\hline Parameter & Value & Unit \\
\hline Capacity & 1380 & $\mathrm{Ah}$ \\
Nominal voltage & 12 & $\mathrm{~V}$ \\
Voltage at no charge & 1.9 & $\mathrm{~V}$ \\
AC/DC inverter efficiency & 0.9 & -- \\
Maximum round efficiency & 0.9 & -- \\
Minimum round efficiency & 0.7 & -- \\
\hline
\end{tabular}

The overall component for PV-battery module in TRNSYS is illustrated in Figure 4, where the weather condition model reads weather data such as outdoor temperature and solar radiation at each time 
step from typical meteorological year weather file and converts them into a desired system of units, which generates all the weather variables that PV panel model needs. The weather file used in this module is the same as the one used in the building module. Both of them are the same TMY3 weather files for Philadelphia, which can easily be replaced with real weather condition files and other weather files for other locations. The "MATLAB Controller" component is connected with the overall "operation module," which passes the overall operation signals into the PV-battery module, such as schedules for "PV charging battery," "PV providing power to building," "Battery discharging power to building."

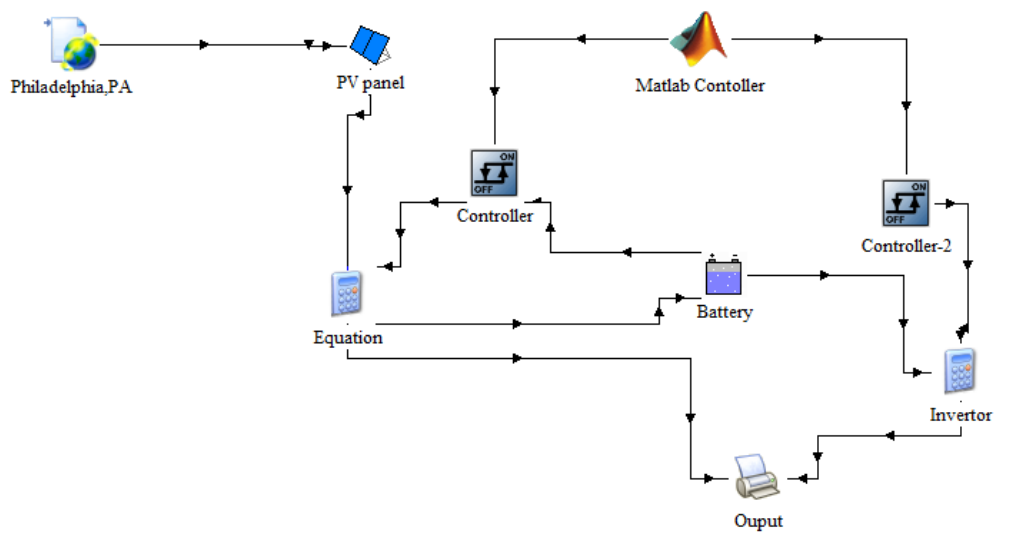

Figure 4. PV panel-battery system model in TRNSYS

\subsection{Ice Tank Thermal Storage Module}

Ice tank thermal energy storage system is another important building energy management equipment, which is often used to reduce the high electricity demand from cooling load during peak hours associated with real-time electricity price. The default ice tank model (object) in EnergyPlus is chosen in this study for its accuracy and robustness. There are two different ice tank thermal storage objects in EnergyPlus: simple model and detailed model. The detailed model allows user-defined charging and discharging curves to model a specific ice storage device more closely [27], which is used in this study. There are three different operation modes in this model, namely dormant mode, charging mode, and discharging mode. In charging or discharging modes, the SOC of the ice tank can be calculated from charging or discharging rate $(u)$, as shown in Eq. 2. During the discharging period, the ice tank storage system provides cooling to meet the cooling demand from the demand side. The chilled water flow rate $\left(\dot{m}_{\text {ice }}\right)$ is 
adjusted according to the load request $\left(\dot{Q}_{i c e}\right)$ and inlet chilled water temperature $\left(T_{\text {inlet }}\right)$, as shown in Eq. 3 [28]:

$$
\begin{gathered}
S O C_{t}=u \Delta t+S O C_{t-\Delta t} \\
\dot{m}_{\text {ice }}=\frac{\dot{Q}_{\text {ice }}}{C_{p}\left(T_{\text {inlet }}-T_{\text {stp }}\right)} .
\end{gathered}
$$

Because the default ice tank storage system model in EnergyPlus needs to be attached to a specific building, which cannot be shared with multiple buildings, a novel ice tank model configuration is developed in this emulator. As illustrated in Figure 2, the ice tank system is modeled as an individual EnergyPlus model with a dedicated chiller. In the ice tank model, chilled water discharged from the ice storage system is sent to the different buildings separately. The ratio of the chilled water mass flow rate for each building is determined by the operation module. The cooling load of each building is covered first by the chilled water from the shared ice storage tank. The remaining cooling need is satisfied by the base chillers of each building. A dedicated chiller is used to charge the ice storage system. The charging and discharging schedule is controlled by the operation module through the dedicated chiller using chilled water outlet temperature setpoints [27]. Key parameters of the ice storage system module are summarized in Table 6.

Table 6. Ice thermal storage tank and dedicated chiller parameter

\begin{tabular}{ccc}
\hline Parameter & Value & Unit \\
\hline Ice Tank Capacity & 0.2 & GJ \\
Tank Loss Coefficient & 0.0003 & -- \\
Freezing Temperature & 0 & C \\
Dedicated Chilled Capacity & 7000 & W \\
Dedicated Chilled COP & 3.2 & --
\end{tabular}

With the ice tank model as an individual model, it is very important to share and exchange chilled water from ice tank to other building models. However, it is very difficult to split the chilled water flow in one EnergyPlus model and connect to another one. The following schemes are used to mimic the mass and heat transfer between the ice storage system and the buildings described above. A user-defined "load profile" model is developed in the chilled water demand loop of ice storage tank to represent the chilled 
water request from all the buildings. The amount of chilled water request is determined in the operation module. Therefore, the ice storage tank will cover the load request in this "load profile," representing the coverage of the building's cooling requests. The overall schematic of the chilled water loop of the ice storage system is illustrated in Figure 5a. To simulate the chilled water received by each building model, a new user-defined component, "ice cooling," is created in the supply side of the chilled water loop within each building model. Similar to a series chiller configuration, the new "ice cooling" component is in a series configuration before the base chiller. The "ice cooling" component will cover some part of the cooling load first, and the base chiller will then cover the remaining cooling loads. The building chilled water loop configuration is illustrated in Figure 5b.

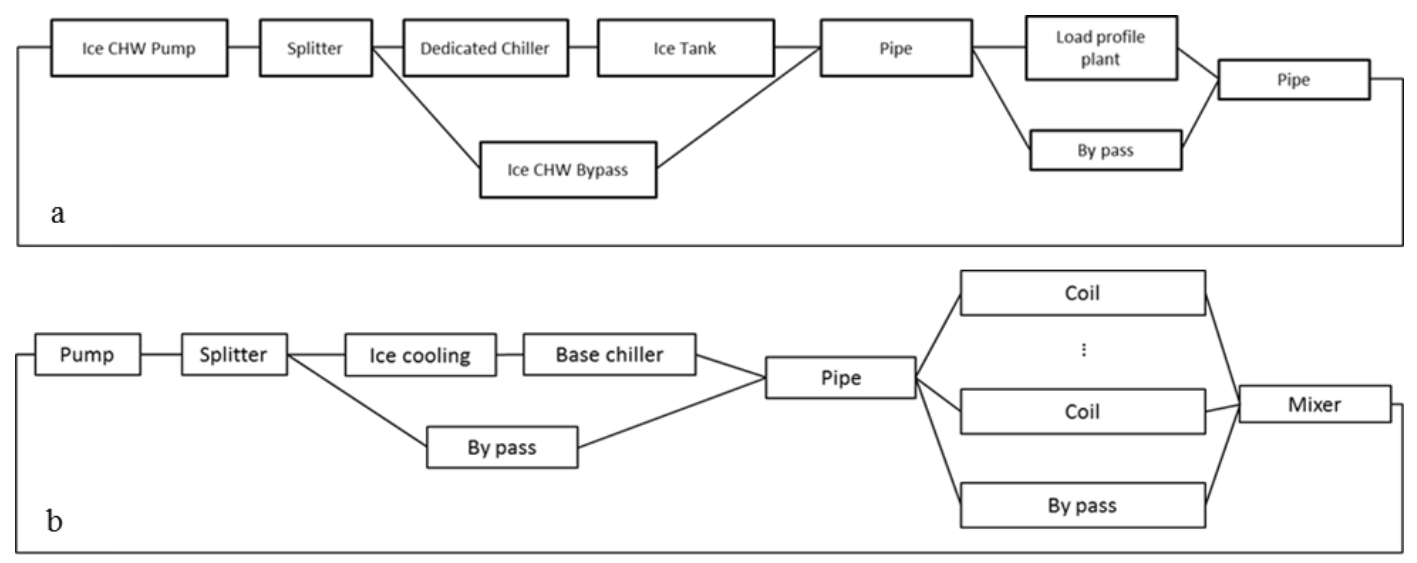

Figure 5 (a): Ice tank thermal storage system configuration; (b): building chilled water configuration

Appendix A provides the detailed program for "ice cooling" model development and chilled water exchanging. The overall schematic of "ice cooling" is illustrated in Figure 6.

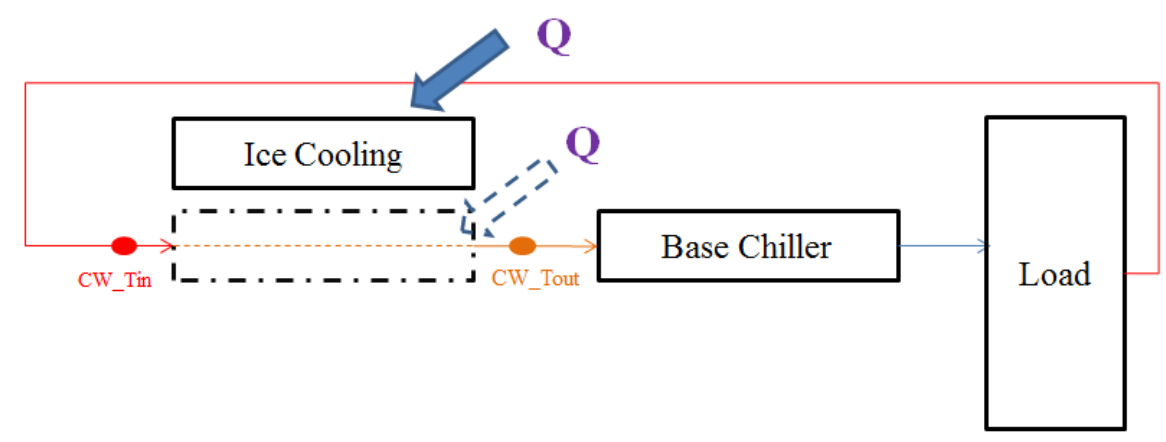

Figure 6. "Ice cooling" component schematic 
As introduced before, the temperature of returning chilled water will be decreased by the "ice cooling" component and then sent into the base chiller:

$$
T_{C W o u t}=T_{C W i n}-\left(\frac{Q_{i c e}}{M_{C W} \cdot C P_{C W}}\right.
$$

where $T_{C W o u t}$ is the chilled water temperature at the outlet of the ice cooling component, which is also the chilled water temperature at the inlet of the base chiller, $T_{C W i n}$ is the chilled water temperature at the inlet of the ice cooling component, $Q_{i c e}$ is the building request cooling from the ice storage tank, $M_{C W}$ is the chilled water mass flow rate in the chilled water loop, and $C P_{C W}$ is the specific heat of chilled water.

\subsection{Operation Module}

The major role of the MATLAB operation module is to provide operation strategies for the whole building cluster. It can also work with optimization methods to determine the building cluster operation signals. The objective of this study is to develop an emulator for building cluster simulation and provide real-world-like operation data to evaluate the performance of the proposed operation strategies. All the control signals, either generated from optimization models or provided by the users, will be combined in this operation module and then sent to other simulation modules. The format of the control signals is shown in Eq. 5:

$$
S=\left[T_{d c, s t p}, Q_{\text {icetot }}, T_{H}^{i}, T_{C}^{i}, P_{P B}^{i}, Q_{i c e}^{i}, S_{P V}, S_{b a t}, S_{i c e}\right],
$$

where $T_{d c, s t p}$ and $Q_{\text {icetot }}$ are signals controlling the ice storage tank, that is, ice storage dedicated chiller outlet water temperature setpoint and total cooling request from all the buildings, respectively; $T_{H}^{i}, T_{C}^{i}, P_{P B}^{i}$, and $Q_{i c e}^{i}$ are the control signals to $i$ th building; $T_{H}^{i}$ and $T_{C}^{i}$ are heating and cooling temperature setpoints; $P_{P B}^{i}$ is the electricity provided to the building from PV and battery system; $Q_{i c e}^{i}$ is the cooling provided to the building from ice storage tank; and $S_{P V}, S_{b a t}$, and $S_{i c e}$ are the operation status (charging, discharging, or dormant) of PV panel, battery, and ice tank systems, respectively. The reason why $T_{d c, s t p}$ is provided in the operation module is that the charging and discharging schedule of the ice storage thermal storage model in EnergyPlus is controlled by the dedicated chiller outlet temperature and the ice storage outlet 
temperature setpoints. Details of the ice tank operation control in EnergyPlus can be found in EnergyPlus Input-Output Reference [27].

\section{Emulator Module Connection}

\subsection{Virtual Power Generator Model in EnergyPlus}

Because the PV panel and battery system are modeled in TRNSYS, a "virtual power generator" model is created in the building models to represent the electricity provided from the PV-battery module (Figure 7). This virtual power generator will be controlled by "TrackSchedule" scheme [27] to generate the same amount of power as that provided by the "PV-battery" module. This power generation value is first simulated in the TRNSYS PV-battery module and then imported into the MATLAB "operation module," and finally transferred to the virtual power generator in EnergyPlus through the BCVTB. Energy management system (EMS) is used to develop the "virtual power generator" and exchange the information through an external interface. Appendix A provides the detailed EMS program for this interconnection between PV-battery and building modules.

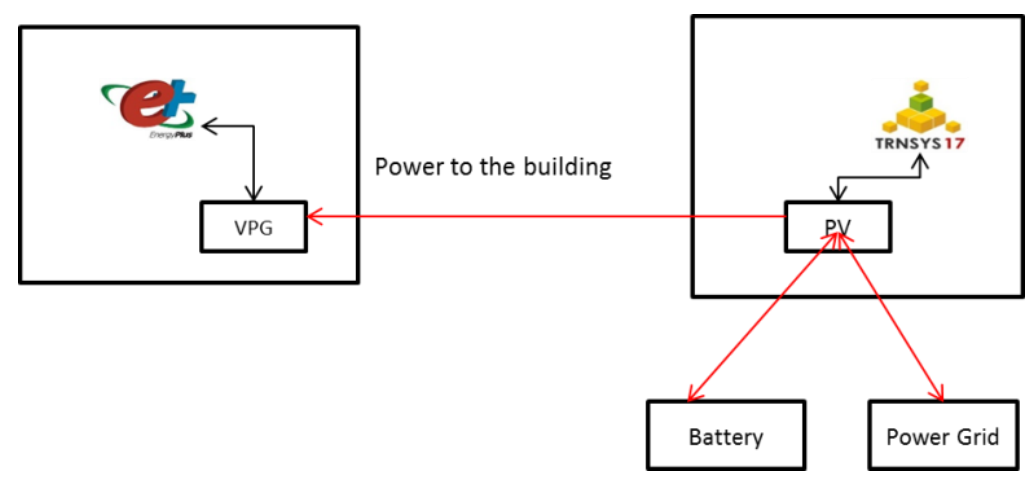

Figure 7. Virtual power generator (VPG) configuration

\subsection{Energy Cost Estimation Model}

All these submodels in this building cluster, such as building models, PV-battery models, and ice tank storage models, are connected to the power grid, where electricity price plays a key role in determining operation strategies. It is noted that a number of public utility commissions and utilities have started to use time-of-use (TOU) electricity price or even real-time price. Real-time pricing usually 
focuses more on large commercial and industrial customers. For small commercial buildings, TOU price is much more common. Figure 8 shows the TOU electricity price plan used in this project (SCE, 2008).

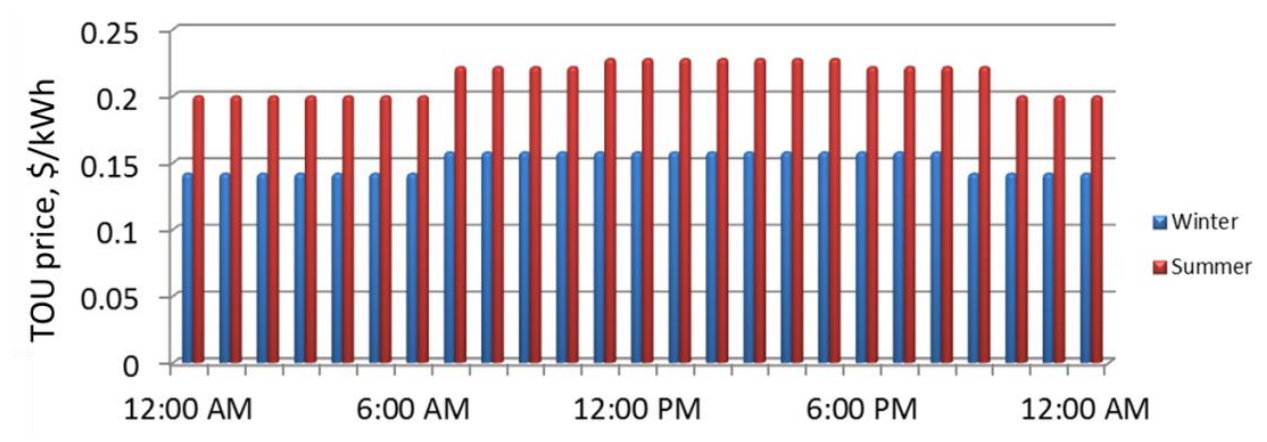

Figure 8.Time-of-Use electricity price

On the basis of this TOU price, an energy cost estimation model is then developed to calculate the electricity cost based on the amount of electricity bought from and sold to the power grid. The total energy cost of this building cluster can be estimated as

$C_{g}=\sum_{i=1}^{m} \sum_{j=1}^{H}\left(R_{p, i, j} P_{t o u, j}-R_{s, i, j} P_{s, j}\right)$,

Eq. 6

where $C_{g}$ is the net electricity cost ( $\$$ for the demonstration case), $\mathrm{m}$ is the number of the buildings in this cluster emulator, $\mathrm{H}$ is the building operation time, and all other variables have been introduced in Table 1.

\subsection{Emulator Realization in BCVTB}

In this project, all the developed modules and models are connected with each other through BCVTB, as shown in Figure 9. The "EnergyPlus I" and "EnergyPlus II" are the building simulators. The "Ice Tank" is the ice storage tank simulator. The "MATLAB" simulator is the operation module and PV-battery TRNSYS module connector, which will provide operation and control signals and call the PV-battery TRNSYS module at every time step. To be more specific of the connection, an external interface is created in these three EnergyPlus models, which is used to connect EnergyPlus with BCVTB through a built-in Ptolemy server. Once EnergyPlus model and BCVTB are connected, the control signals for the building module are transferred though this interface from BCVTB to EnergyPlus models during the simulation. Meanwhile, the control signals from the operation module are sent to BCVTB through a 
shared socket connection from MATLAB. Appendix A provides the detailed code for the module connection and interface development.

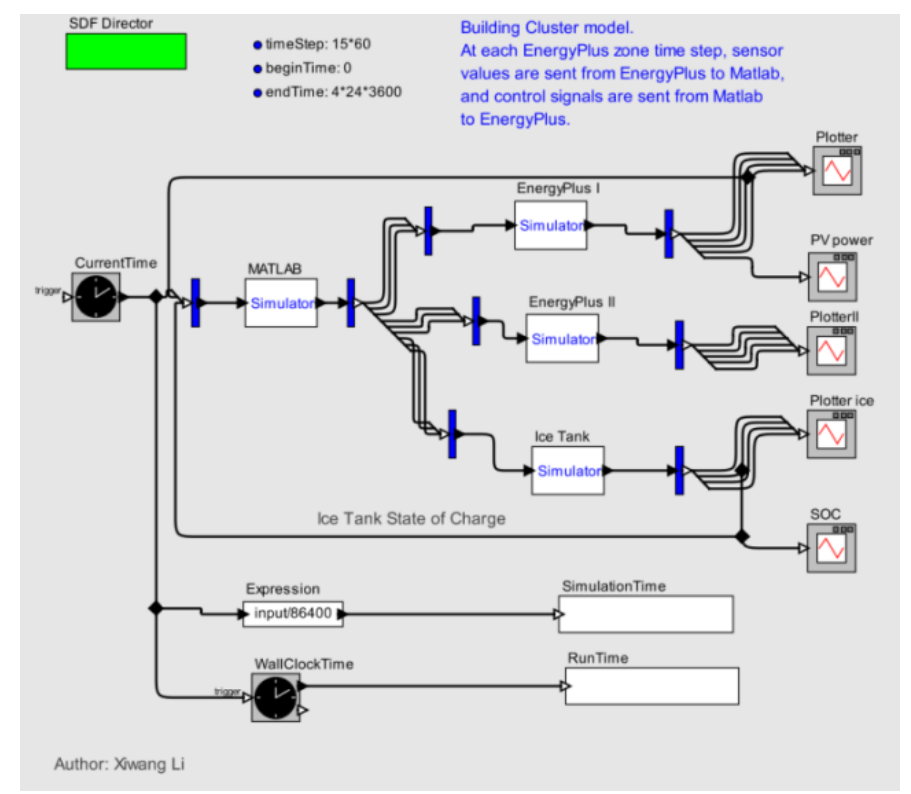

Figure 9. Emulator connection in BCVTB

\section{Emulator Proof-of-Concept Operation Testing}

\subsection{Emulator Testing Scheme}

The development and connection of each module in the building cluster emulator have been discussed. All the models used in this emulator demonstration have been validated in previous studies. Therefore, the operation testing will focus on the module connection and data exchange. Table 7 summarizes the overall testing criteria. This proof-of-concept demonstration will compare results from different modules to check the success of data exchange. This demonstration will also verify the operation of each module against the control signals in the operation module. For example, ice tank should be in charging state if the dedicated chiller outlet temperature setpoint is $-7^{\circ} \mathrm{C}$, and it should be in discharging state if the temperature setpoint is $90^{\circ} \mathrm{C}$.

Table 7. Emulator proof-of-concept testing criteria

\begin{tabular}{cccc}
\hline Category & Model & Checking Variable & Checking Method \\
\hline $\begin{array}{c}\text { Building Control } \\
\text { and operation }\end{array}$ & EnergyPlus & $\mathrm{T}_{\mathrm{H}}, \mathrm{T}_{\mathrm{C}}, \mathrm{T}_{\mathrm{rm}}$ & Compare results of EnergyPlus and MATLAB \\
& $\mathrm{E}_{\mathrm{pv}}, \mathrm{E}_{\mathrm{bldg}}$ & Compare TRNSYS and EnergyPlus
\end{tabular}




\begin{tabular}{|c|c|c|c|}
\hline $\begin{array}{l}\text { Ice tank } \\
\text { operation }\end{array}$ & EnergyPlus & $\begin{array}{c}\mathrm{T}_{\mathrm{dc}, \mathrm{stp}}, \mathrm{Q}_{\text {icetot }}, Q_{i c e}^{i} \\
\mathrm{SOC}_{\text {ice }}\end{array}$ & Tchi for charging and discharging, $\mathrm{Q}$ request and provide, $\mathrm{SOC}_{\mathrm{ice}}$ \\
\hline $\begin{array}{l}\text { PV-battery } \\
\text { system operation }\end{array}$ & TRNSYS & $\begin{array}{l}\mathrm{S}_{\mathrm{pv}}, \mathrm{P}_{\mathrm{pv}}, \mathrm{S}_{\mathrm{bat}} \mathrm{P}_{\mathrm{ba}} \mathrm{t} \\
\mathrm{SOC}_{\mathrm{bat}}\end{array}$ & $\begin{array}{l}\text { Control signals for charging and discharging, power generation, power } \\
\text { to building, grid, and battery, } \mathrm{SOC}_{\mathrm{ba}}\end{array}$ \\
\hline
\end{tabular}

The control signals can be obtained from either optimization models or other predefined operation strategies. It is common knowledge that it is very difficult to use detailed physics-based models to calculate the optimal control strategies, because it is expensive and very time consuming to develop and validate this emulator. In addition, the calculation speed is not fast enough to be used in the searchingbased optimization method. Therefore, in this demonstration, some predefined operation strategies are applied in this emulator.

All the temperature setpoints for building temperature control and ice tank scheduling as well as ice tank load request are summarized in Table 8. Two different sets of heating and cooling setpoints are applied to the building cluster for summer and winter simulation. Ice tank is in charging state at night from 8:00 PM to 8:00 AM until it becomes fully charged and in discharging state from 8:00 AM to 6:00 PM until it depletes. Between 6:00 PM and 8:00 PM, the ice tank will be kept dormant.

Table 8. Building and ice tank settings for summer (winter)

\begin{tabular}{lccccccc}
\hline & \multicolumn{2}{c}{ Building I } & \multicolumn{2}{c}{ Building II } & \multicolumn{2}{c}{ Ice Tank } \\
\cline { 2 - 7 } Time, h & $\begin{array}{c}\text { Heating } \\
\text { setpoint, }{ }^{\circ} \mathrm{C}\end{array}$ & $\begin{array}{c}\text { Cooling } \\
\text { setpoint, }{ }^{\circ} \mathrm{C}\end{array}$ & $\begin{array}{c}\text { Heating } \\
\text { setpoint, }{ }^{\circ} \mathrm{C}\end{array}$ & $\begin{array}{c}\text { Cooling } \\
\text { setpoint, }{ }^{\circ} \mathrm{C}\end{array}$ & $\begin{array}{c}\text { Dedicated } \\
\text { chiller } \\
\text { setpoint, }{ }^{\circ} \mathrm{C}\end{array}$ & $\begin{array}{c}\text { Load request } \\
\text { Building I, W }\end{array}$ & $\begin{array}{c}\text { Load request } \\
\text { Building II,W }\end{array}$ \\
\hline $0-8$ & $18(18)$ & $28(26)$ & $20(18)$ & $22(25)$ & -7 (off) & $0(0)$ & $0(0)$ \\
$8-12$ & $20(22)$ & $22(24)$ & $24(24)$ & $26(26)$ & $90($ off) & $13,000(0)$ & $9000(0)$ \\
$12-18$ & $20(22)$ & $22(24)$ & $24(24)$ & $26(26)$ & $90($ off) & $13,000(0)$ & $9000(0)$ \\
$18-20$ & $20(22)$ & $22(26)$ & $24(24)$ & $26(26)$ & $45($ off) & $0(0)$ & $0(0)$ \\
$20-24$ & $18(18)$ & $28(26)$ & $18(18)$ & $28(25)$ & $-7($ off) & $0(0)$ & $0(0)$ \\
\hline
\end{tabular}

The operation of PV panel and battery system is shown in Table 9. PV panel energy generation will charge battery first and then provide power to buildings. In summer, the ice tank is charged by a dedicated chiller at night and discharges chilled water to buildings in the peak hours. The ice tank is kept completely off in winter. The building cluster test operation results under these operation strategies will be discussed in the following sections.

Table 9. PV-battery and ice tank schedule 


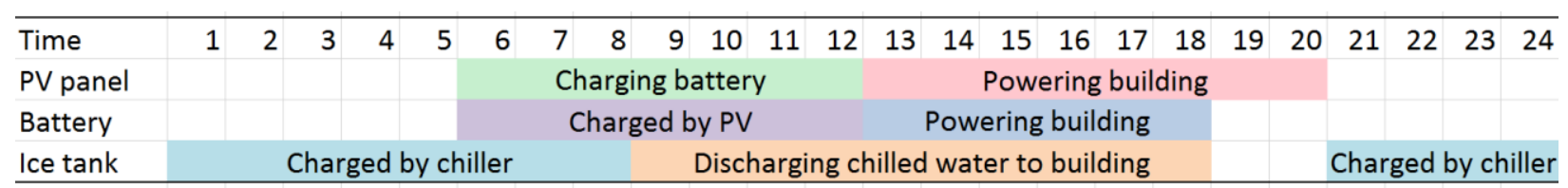

\subsection{Emulator Testing Results}

\subsubsection{Building Cluster Simulation Results}

The proof-of-concept study is conducted on August $1^{\text {st }}$ for summer case and on January $3^{\text {rd }}$ for winter case. The location of this building cluster is Philadelphia, PA, USA. Figure 10 shows the temperature simulation results of these two buildings from EnergyPlus for summer and winter simulations. These two building models use the same weather condition file and internal load schedule, but different temperature setpoints. In these two plots, the heating and cooling setpoints are identical to their operation settings in the operation module (Table 8), and the building room temperature is effectively controlled by the temperature setpoints. In Figure 10 (a), room temperature is beyond control from 8:00 AM to 5:00 PM in the summer case. This is because the cooling demand exceeds the capacity of the air conditioning system. The room temperature is under control in all other cases.
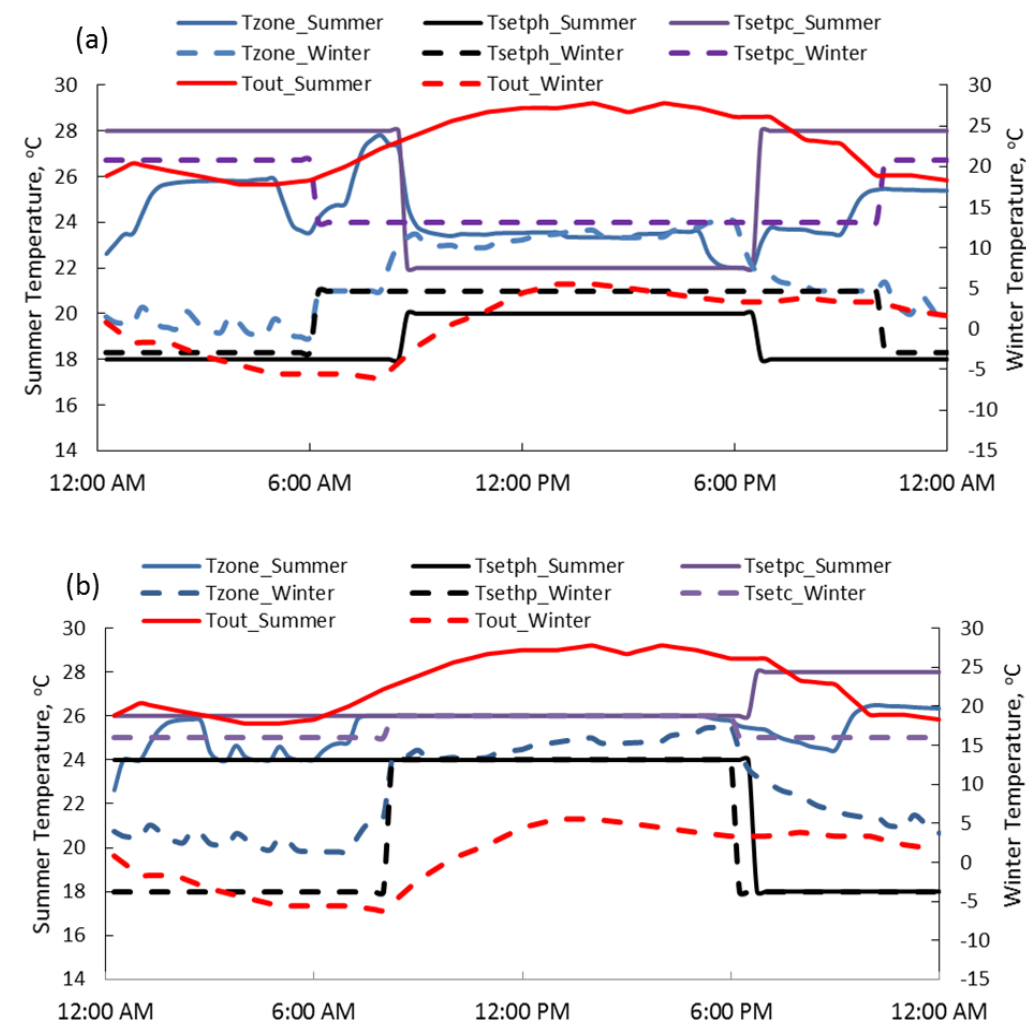

Figure 10. Building temperature simulation results: (a) building I and (b) building II 
Similarly, Figure 11 plots the PV-battery module simulation results. Identical to the operation signals in Table 8, PV panel starts to charge battery in early morning and provides power to the building after the battery is fully charged. Starting from 12:00 PM, the PV panel and battery provide power to the buildings together to reduce the peak demand. In the PV-battery model, $60 \%$ of the outputted power is provided to building I, which is the same as the control signals.

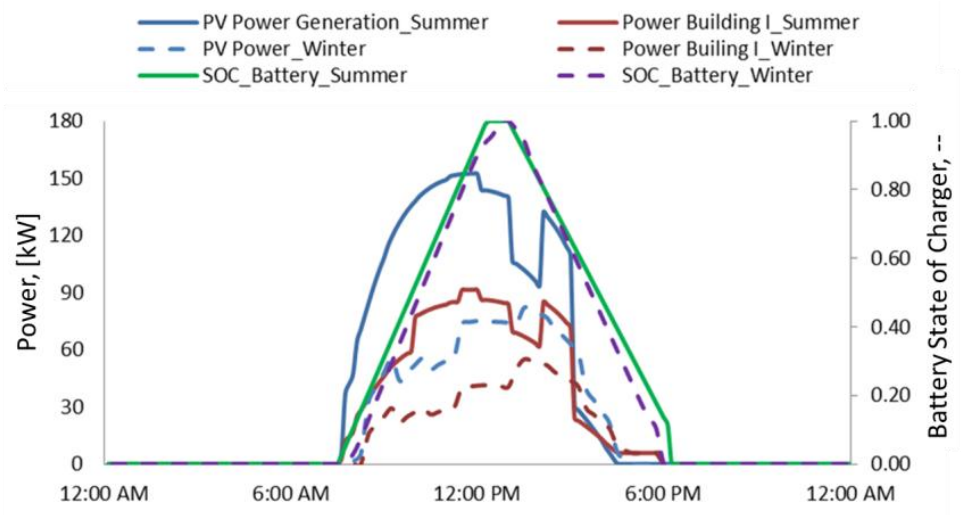

Figure 11. PV-battery operation results

As predetermined in Table 8, the shared ice storage tank is covering part of load for building I and building II from 9:00 AM to 9:00 PM, until the ice tank is depleted. The simulation results are shown in Figure 12. The blue line shows the ice tank storage SOC, which stays full until 8:00 AM when it starts to discharge until it is depleted. During the discharge period, the dedicated chiller is also working to meet the cooling requirement of the buildings. The green line is the amount of ice cooling provided to building I, which is $60 \%$ of the total discharged rate (red line). This test validates the ice tank share method described in Section 2.3.

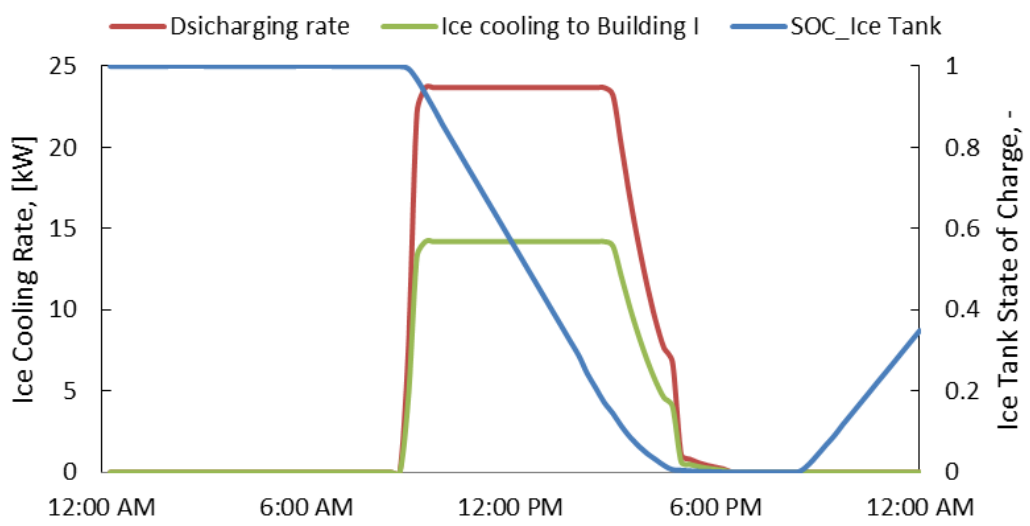


Figure 12. Ice tank operation results

\subsubsection{Building Cluster Energy Consumption and Cost}

The energy consumption and the cost of the building cluster under the testing condition are shown in Figure 13. The energy cost does not include peak demand charging, which is usually for large commercial and industrial buildings. The energy consumption at peak hours, from 12:00 PM to 4:00 PM, is reduced in these two buildings, because of the power generation PV panel and battery power discharging, which would save significant energy cost. During off peak hours, ice tank would be charged by the power grid, utilizing the lower electricity price. Building type and thermal mass significantly affect the building energy consumption and operation. In this study, building II is larger than building I, and hence consumes more energy (Table 10). The peak demand of building I is approximately $80 \mathrm{~kW}$, which is less than the power provided by peak PV-battery. Therefore, the electricity purchasing is zero at noon for about $30 \mathrm{~min}$. From the simulation results, the PV-battery power provided $886.2-\mathrm{kWh}$ electricity and saved US \$205.6, without considering the peak demand charging.
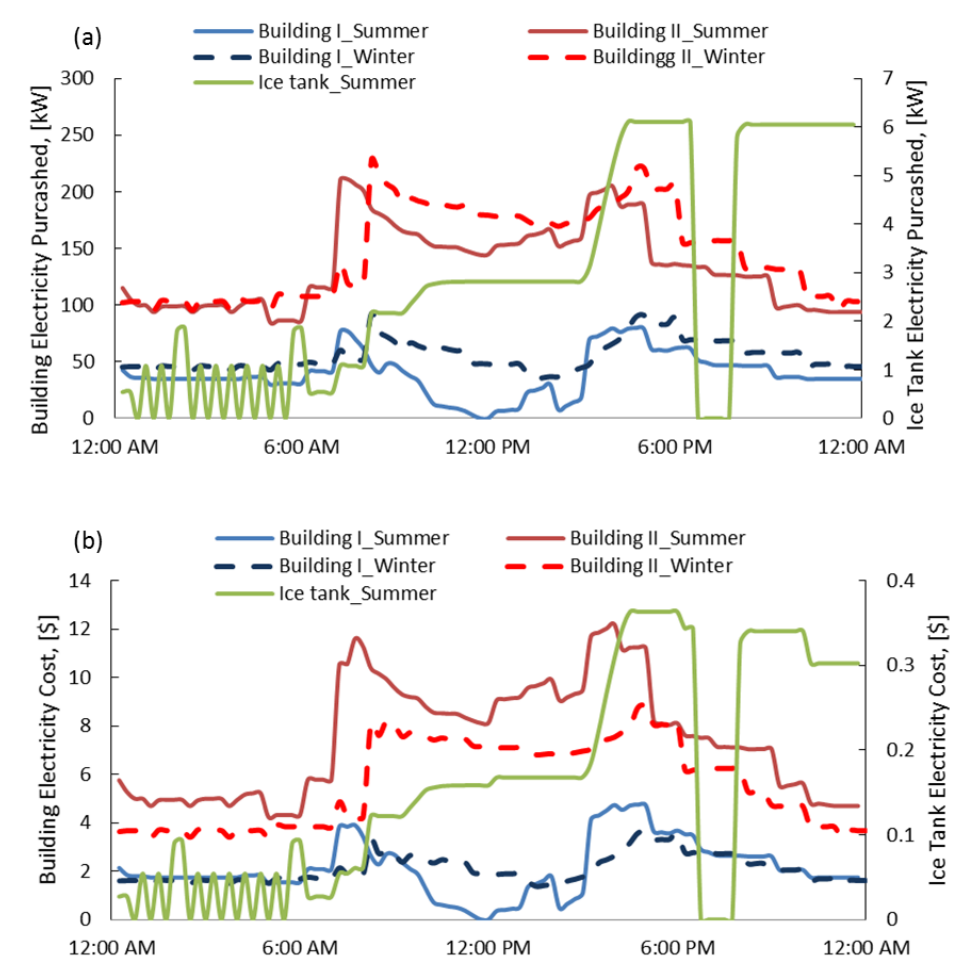

Figure 13. Building electricity consumption and cost 
Table 10. Building cluster electricity consumption summary

\begin{tabular}{lcccccc}
\hline & \multicolumn{2}{c}{ Electricity Consumption [kWh] } & \multicolumn{2}{c}{ Electricity Cost [US \$] } & \multicolumn{2}{c}{ Peak Demand [kW] } \\
& Building I & Building II & Building I & Building II & Building I & Building II \\
\hline Summer Case & 927.5 & 3214.8 & 203.1 & 711.5 & 79.7 & 210.9 \\
Winter Case & 1325.2 & 3520.0 & 291.7 & 781.7 & 92.6 & 227.7 \\
\hline
\end{tabular}

\section{Conclusions and Future Work}

In this study, an emulator test bed, which is designed to assess building cluster operation strategies and simulate a building cluster as well as energy generation and storage devices, is developed. In this building cluster emulator, multiple buildings are connected and can share PV panels as energy generation devices and battery and ice tank as energy storage systems. Various simulation environments, including EnergyPlus and TRNSYS, are used to model different parts of this building cluster and are interconnected through the BCVTB to the MATLAB model. A proof-of-concept test case is conducted to illustrate the use of this test bed and verify the data exchange within this emulator. Comparing building I and building II, however, building thermal mass as an important building characteristic plays a significant role in building operation and energy savings. Weather conditions such as outdoor air temperature and solar radiation also greatly affect the energy consumption and energy generation. On the contrary, energy costs of the cluster during off-peak and on-peak periods show that building operation, especially the operation of energy generation and storage devices, should be updated according to the electricity price changing to fully utilize electricity at low rate in off-peak hours. Future studies will focus on testing the data exchanging of this emulator with real buildings and distributed energy systems.

\section{Appendix A}

\section{Building Cluster Emulator Setup}

1. EnergyPlus and BCVTB Connection

EnergyPlus and BCVTB are connected using Ptolemy through the external interface in EnergyPlus. Figure A-1and Figure A-2 show the external interface and transferring variables. 


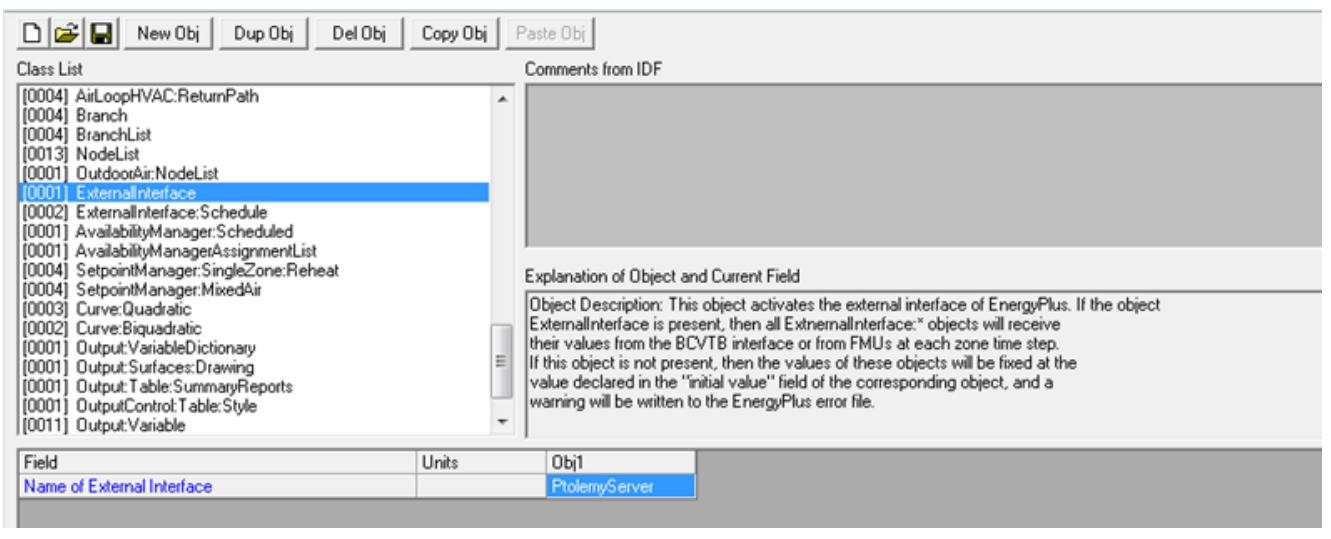

Figure A-1 External interface in EnergyPlus

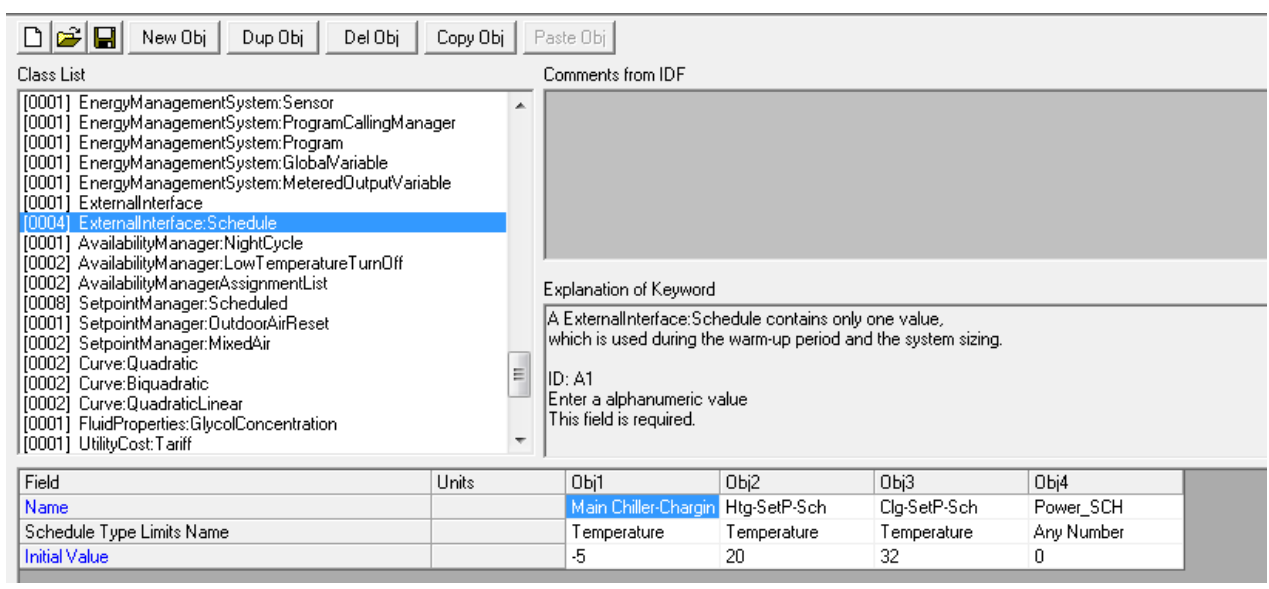

Figure A-2 Control variable transferring

To declare the data exchange, a configuration file is also needed:

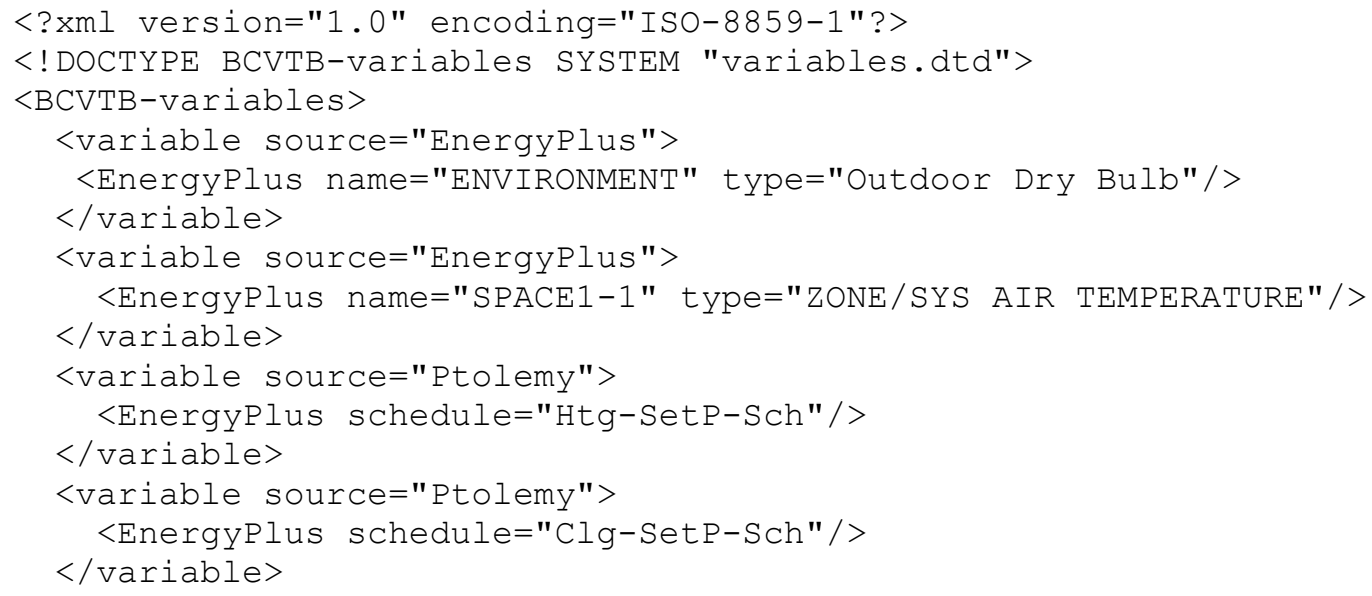




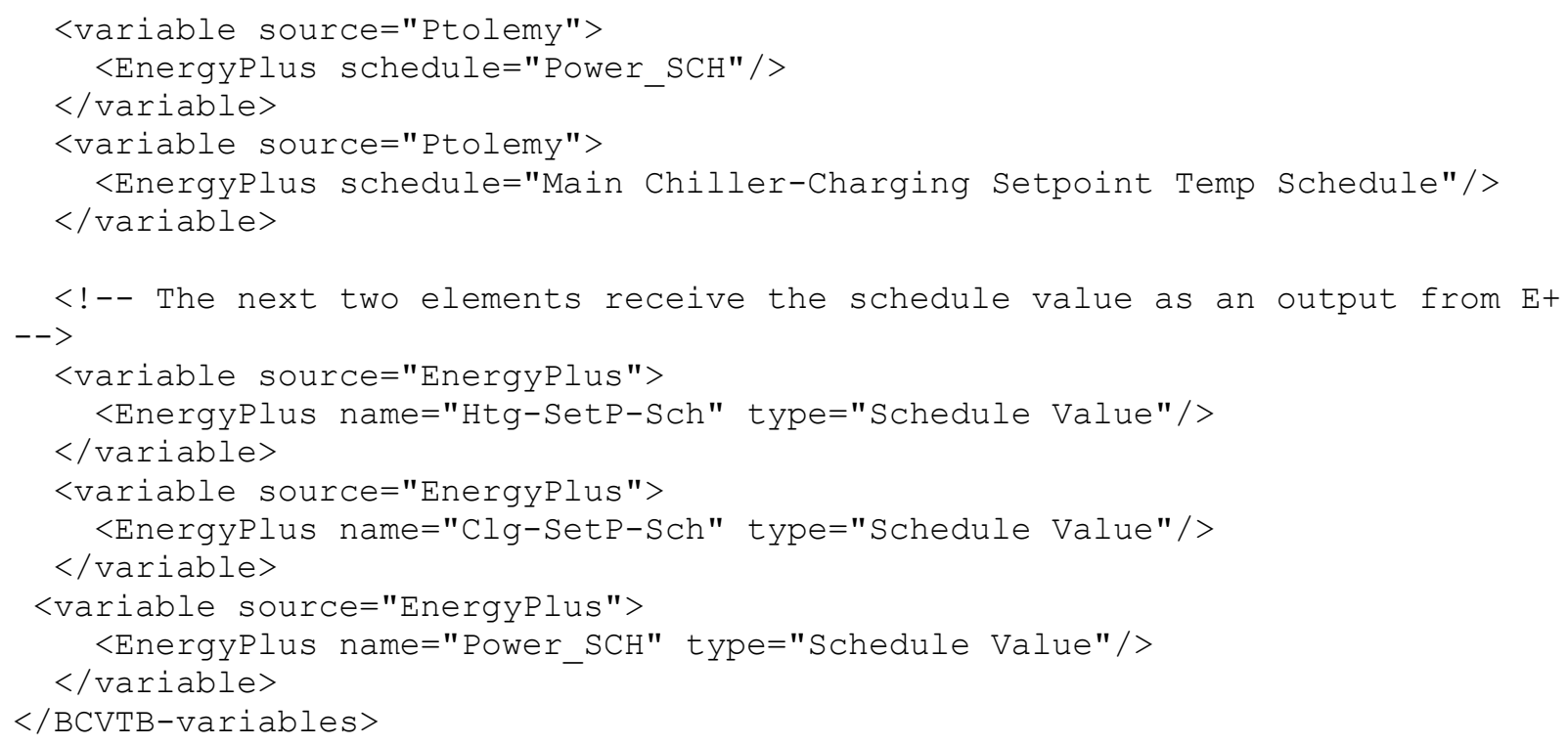

\section{TRNSYS and BCVTB Connection}

There is a MATLAB module in BCVTB for MATLAB, and TRNSYS and BCVTN are connected through MATLAB:

dos ('C: \TRNSYS17\Exe \TRNExe.exe

$\mathrm{C}: \backslash T R N S Y S 17 \backslash$ MyProjects $\backslash$ Project $1 \backslash$ Project1_test.dck / n')

응 reading TRNSYS results

fid=fopen ('C: \TRNSYS17\MyProjects \Project1 \Project1_test.out', 'rt' ) ;

if fid $==-1$ pout='Can not open sor file' pout='There is an error, please use control c to stop the program' 


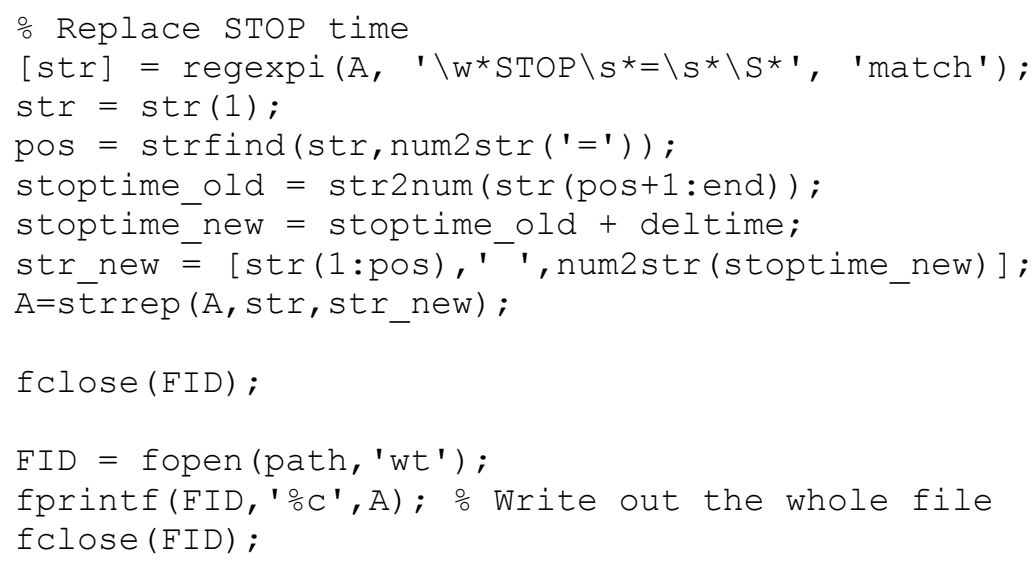

\section{EnergyPlus EMS for ice tank module:}

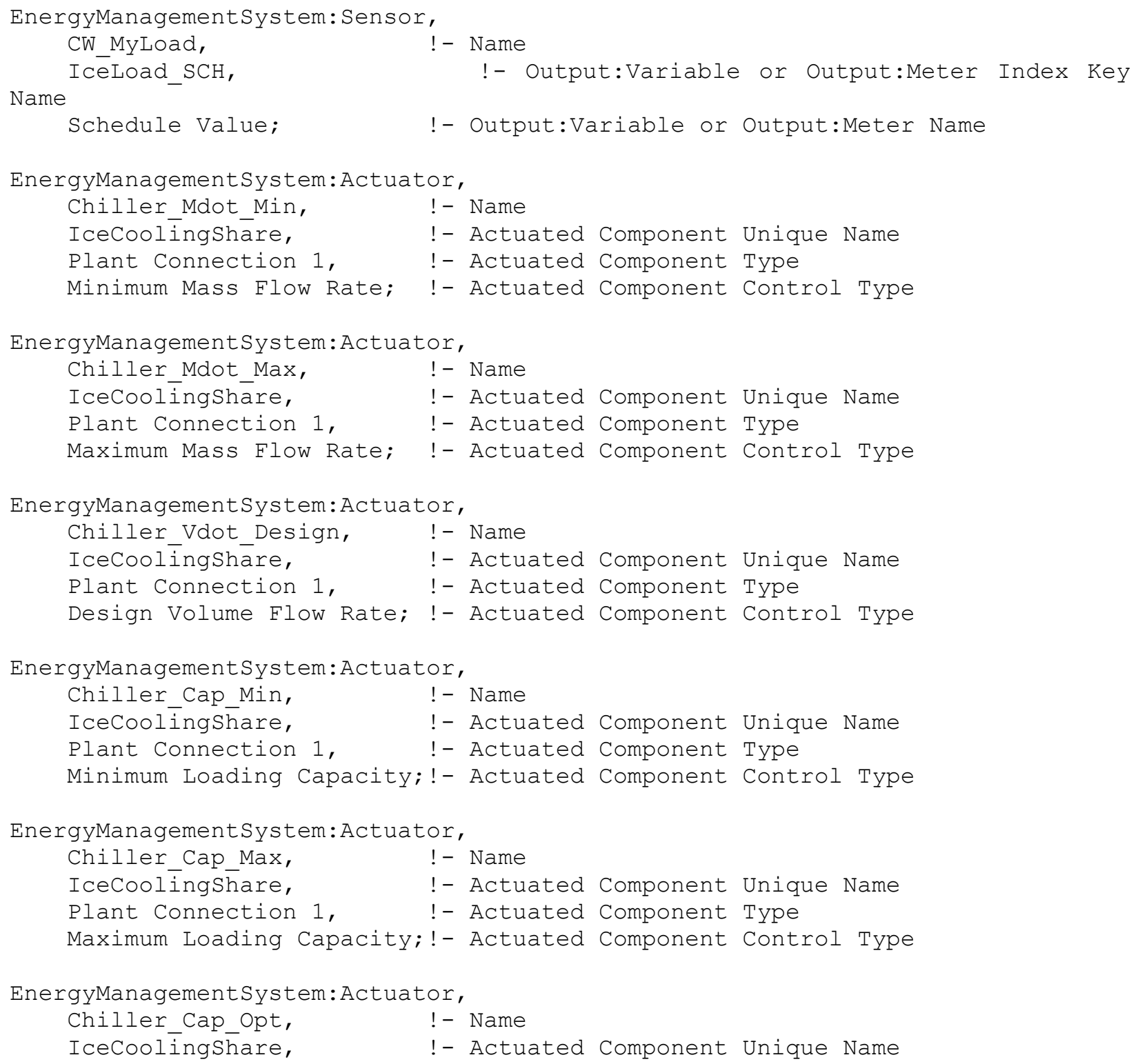


Plant Connection 1, !- Actuated Component Type

Optimal Loading Capacity; !- Actuated Component Control Type

EnergyManagementsystem: Actuator,
CW_Tout,
! - Name
Icecoolingshare,
! - Actuated Component Unique Name
Plant Connection 1 ,
!- Actuated Component Type
Outlet Temperature;
!- Actuated Component Control Type

EnergyManagementSystem:ProgramCallingManager, Cooling share init model, !- Name

UserDefinedComponentModel, !- EnergyPlus Model Calling Point

ShareCoolingInitModel; !- Program Name 1

EnergyManagementSystem: ProgramCallingManager, Cooling share simulation model, !- Name

UserDefinedComponentModel, !- EnergyPlus Model Calling Point

ModelShareModel; !- Program Name 1

EnergyManagementSystem: Program,

ShareCoolingInitModel, !- Name

Set CWLoopExitTemp $=10.0$, !- Program Line 1

Set CWLoopDeltaTemp $=4.0, !$ - Program Line 2

Set $\mathrm{CW} C P=$ aCPCW CWLoopExitTemp, !- $\mathrm{A} 4$

Set CW rho = @RhoH20 CWLoopExitTemp, !- A5

Set Chiller_Vdot_Design = CWplant_Vdot_Design, !- A6

Set Chiller_Mdot_Min $=0.0, \quad !-A \overline{7}$

Set Chiller Mdot ${ }^{-}$Max $=$Chiller Vdot Design * CW rho, ! - A8

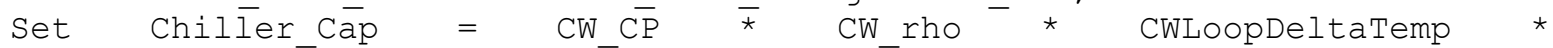

CWplant Vdot Design, !- A9

Set Chilier_Cap_Min $=0.0, \quad !-A 10$

Set Chiller_Cap_Max = Chiller_Cap; !-A11

EnergyManagementSystem: Program,

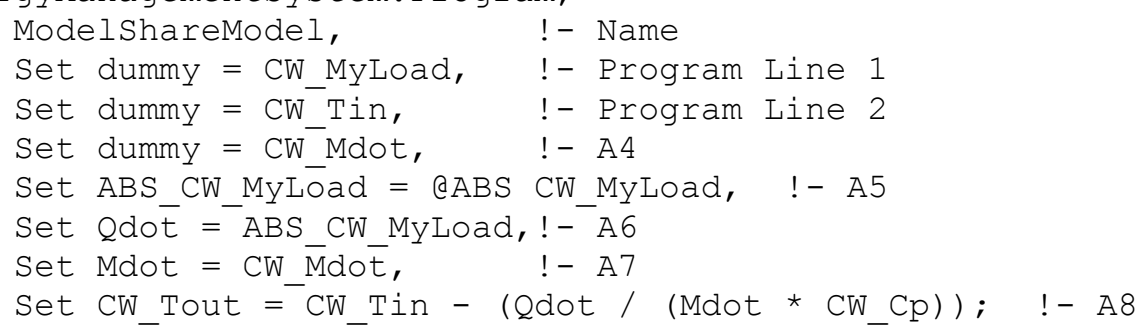




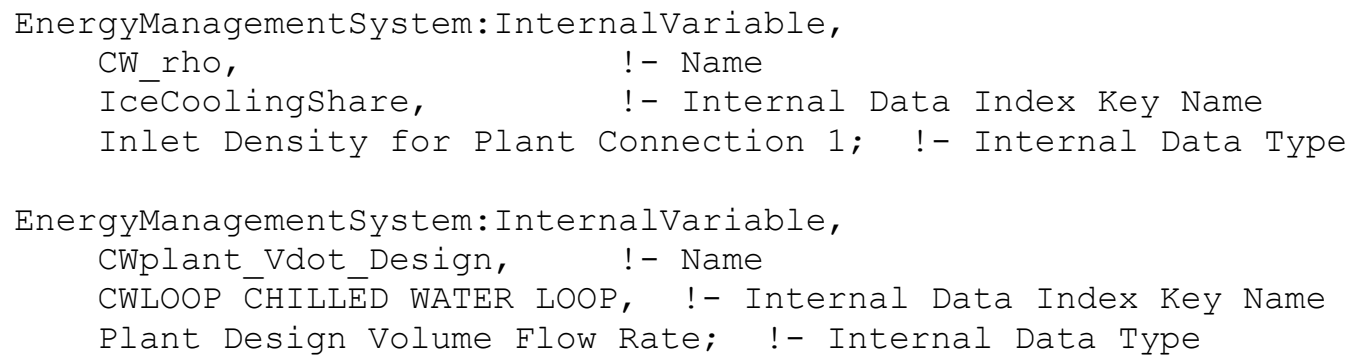

\section{Acknowledgments}

Part of this study was conducted at Drexel University. Financial support from the National Science Foundation (award number: 1239257) is highly appreciated. The author is also grateful to the Postdoctoral Fellowship from the Center for Green Buildings and Cities at Harvard University.

\section{Reference}

1. DOE, U.S. Buildings Energy Data Book, http://buildingsdatabook.eren.doe.gov/. 2013.

2. Katipamula, S. and M.R. Brambley, Review Article: Methods for Fault Detection, Diagnostics, and Prognostics for Building Systems-A Review, Part I. HVAC\&R Research, 2005. 11(1): p. 325.

3. National Energy Technology Laboratory (NETL), Demand Dispatch-Intelligent Demand for a More Efficient Grid, DOE/NETL-DE-FE0004001, Editor. August 2011: Morgantown, West Virginia.

4. Friedman, H., Wiring the smart grid for energy savings: Integrating buildings to maximize investment. 2009: Portland, Oregon: Portland Energy Conservation Inc. (PECI.).

5. Xiao, F., et al., Bayesian network based FDD strategy for variable air volume terminals. Automation in Construction, 2014. 41: p. 106-118.

6. Attia, S., et al., Simulation-based decision support tool for early stages of zero-energy building design. Energy and Buildings, 2012. 49: p. 2-15.

7. Zhao, Y., J. Wen, and S. Wang, Diagnostic Bayesian networks for diagnosing air handling units faults - Part II: Faults in coils and sensors. Applied Thermal Engineering, 2015. 90: p. 145-157.

8. Dexter, A. and J.F. Pakanen, Fault detection and diagnosis methods in real buildings., in Energy Conservation in Buildings and Community Systems, IEA Annex 34: Computer-aided evaluation of HVAC system performance. 2001.

9. Wang, S. and F. Xiao, AHU sensor fault diagnosis using principal component analysis method. Energy and Buildings, 2004. 36(2): p. 147-160.

10. Building Energy Software Tools.

11. Bonvini, M., et al., Robust on-line fault detection diagnosis for HVAC components based on nonlinear state estimation techniques. Applied Energy, 2014. 124: p. 156-166.

12. Lee, K.-H. and J.E. Braun, Development of methods for determining demand-limiting setpoint trajectories in buildings using short-term measurements. Building and Environment, 2008. 43(10): p. 1755-1768.

13. Ma, J., et al., Demand reduction in building energy systems based on economic model predictive control. Chemical Engineering Science, 2012. 67(1): p. 92-100.

14. Hajiah, A. and M. Krarti, Optimal control of building storage systems using both ice storage and thermal mass - Part I: Simulation environment. Energy Conversion and Management, 2012. 64(0): p. 499-508.

15. Mulder, G., F.D. Ridder, and D. Six, Electricity storage for grid-connected household dwellings with PV panels. Solar Energy, 2010. 84(7): p. 1284-1293. 
16. Oldewurtel, F., et al., Use of model predictive control and weather forecasts for energy efficient building climate control. Energy and Buildings, 2012. 45: p. 15-27.

17. Li, X. and J. Wen, Review of building energy modeling for control and operation. Renewable and Sustainable Energy Reviews, 2014. 37: p. 517-537.

18. Lamoudi, M.Y., P. Béguery, and M. Alamir. Use of simulation for the validation of a model predictive control strategy for energy management in buildings. in Proceedings of Building Simulation. 2011.

19. Maasoumy, M., et al. Selecting building predictive control based on model uncertainty. in American Control Conference (ACC), 2014. 2014. IEEE.

20. House, J.M., W.Y. Lee, and D.R. Shin, Classification techniques for fault detection and diagnosis of an air-handling unit. Transactions of ASHRAE, 1999. 105: p. 1087-1100.

21. Crawley, D.B., et al., EnergyPlus: creating a new-generation building energy simulation program. Energy and Buildings, 2001. 33(4): p. 319-331.

22. De Soto, W., S.A. Klein, and W.A. Beckman, Improvement and validation of a model for photovoltaic array performance. Solar Energy, 2006. 80(1): p. 78-88.

23. Kim, S.H., Building demand-side control using thermal energy storage under uncertainty: An adaptive Multiple Model-based Predictive Control (MMPC) approach. Building and Environment, 2013. 67: p. 111-128.

24. Wetter, M. and P. Haves, A Modular building controls virtual test Bed for the Integration of heterogeneous systems, in Proceedings of 3rd Nation Conference of IBPSA-USA SimBuild 2008: Berkeley, California.

25. Liam Hendricken, et al., Capital Costs and Energy Savings Achieved by Energy Conservation Measures for Office Buildings in the Greater Philadephia Region, in SimBuild 2012: Madison, WI.

26. Fry, B.A., Simulation of Grid-Tied Building Integrated Photovoltaic Systems. Master's Thesis, University of Wisconsin-Madison, 1998.

27. DOE, U., EnergyPlus Engineering Reference. Input and Output Reference, 2013: p. 6.

28. Ihm, P., M. Krarti, and G.P. Henze, Development of a thermal energy storage model for EnergyPlus. Energy and Buildings, 2004. 36(8): p. 807-814. 